\title{
Conviviality and collectives on social media: Virality, memes, and new social structures
}

\author{
Piia Varis \\ Tilburg University \\ Jan Blommaert \\ Tilburg University and Ghent University
}

\begin{abstract}
There is a long tradition in which 'phatic' forms of interaction are seen as (and characterized by) relatively low levels of 'information' and 'meaning'. Yet, observations on social media interaction patterns show an amazing density of such phatic interactions, in which signs are shared and circulated without an a priori determination of the meaning. We address the issue of 'virality' in this paper: the astonishing speed and scope with which often 'empty' (i.e. not a priori determined) signs circulate online. We address 'memes' - signs that have gone viral on the internet-as cases in point. Virality as a sociolinguistic phenomenon raises specific issues about signs, meanings, and functions, prompting a shift from 'meaning' to 'effect'. This effect, we can see, is conviviality: the production of a social-structuring level of engagement in loose, temporal, and elastic collectives operating in social media environments.
\end{abstract}

Keywords: phatic communion; social media; virality; memes; meaning; function; community; identity

\section{INTRODUCTION}

$\mathrm{T}$ a very insightful and relatively early 1 paper on the phenomenon, Vincent Miller (2008) questions the 'content' of communication on social media and microblogs (Facebook and Twitter, respectively), and concludes:

We are seeing how in many ways the internet has become as much about interaction with others as it has about accessing information. (...) In the drift from blogging, to social networking, to microblogging we see a shift from dialogue and communication between actors in a network, where the point of the network was to facilitate an exchange of substantive content, to a situation where the maintenance of a network itself has become the primary focus. (...) This has resulted in a rise of what I have called 'phatic media' in which communication without content has taken precedence. (Miller 2008: 398)

Miller sees the avalanche of 'empty' messages on new social media as an illustration of the 'postsocial' society in 
which networks, rather than (traditional, organic) communities, are the central fora for establishing social ties between people. The messages are 'empty' in the sense that no perceptibly 'relevant content' is being communicated; thus, such messages are typologically germane to the kind of 'small talk' which Bronislaw Malinowski (1923 [1936]) identified as 'phatic communion' and described as follows:

'phatic communion' serves to establish bonds of personal union between people brought together by the mere need of companionship and does not serve any purpose of communicating ideas (Malinowski 1923 [1936]: 316).

For Malinowski, phatic communion was a key argument for his view that language should not just be seen as a carrier of propositional contents ('communicating ideas' in the fragment above), but as a mode of social action, the scope of which should not be reduced to 'meaning' in the denotational sense of the term. In an excellent paper on the history of the term 'phatic communion', Gunter Senft notes the post-hoc reinterpretation of the term by Jakobson (1960) as 'channeloriented' interaction, and describes phatic communion as

utterances that are said to have exclusively social, bonding functions like establishing and maintaining a friendly and harmonious atmosphere in interpersonal relations, especially during the opening and closing stages of social - verbal encounters. These utterances are understood as a means for keeping the communication channels open. (Senft 1995: 3)

Senftalso emphasizes the differencebetween 'communion' and 'communication'. Malinowski never used the term phatic 'communication', and for a reason: 'communion' stresses (a) the ritual aspects of phatic phenomena, and (b) the fact that through phatic communion, people express their sense of 'union' with a community. We will come back to this later on.

When it came to explaining the phenomenon, Malinowski saw the fear of silence, understood as an embarrassing situation in interaction among Trobriand Islanders, as the motive underlying the frequency of phatic communion. In order not to appear grumpy or taciturn to the interlocutor, Trobrianders engaged in sometimes lengthy exchanges of 'irrelevant' talk. While Malinowski saw this horror vacui as possibly universal, Dell Hymes cautioned against such an interpretation and suggested that 'the distribution of required and preferred silence, indeed, perhaps most immediately reveals in outline form a community's structure of speaking' (Hymes 1972 [1986]: 40; see Senft 1995: 4-5 for a discussion). There are indeed communities where, unless one has anything substantial to say, silence is strongly preferred over small talk and 'phatic communion' would consequently be experienced as an unwelcome violation of social custom. This is clearly not the case in the internet communities explored by Vincent Miller, where 'small' and 'content-free' talk appears to be if not the rule, then certainly a very wellentrenched mode of interaction.

This, perhaps, compels us to take 'phatic' talk seriously, given that it is so hard to avoid as a phenomenon in social media, for example. And this, then, would be a correction to a deeply ingrained linguistic and sociolinguistic mindset in which 'small talk'-the term itself announces it-is not always perceived as really important or in need of much in-depth exploration. 
Schegloff's (1972; Schegloff and Sacks 1973) early papers on conversational openings and closings described these often routinized sequences as a mechanism in which speaker and hearer roles were established and confirmed. This early interpretation shows affinity with Malinowski's 'phatic communion'-the concern with the 'channel' of communicationas well as with Erving Goffman's (1967) concept of 'interaction ritual' in which people follow particular, relatively perduring templates that safeguard 'order' in faceto-face interaction. In an influential later paper, however, Schegloff (1988) rejected Goffman's attention to 'ritual' and 'face' as instances of 'psychology' (in fact, as too much interested in the meaning of interaction), and reduced the Goffmanian rituals to a more 'secularized' study of interaction as a formal 'syntax' in which human intentions and subjectivities did not matter too much. The question of what people seek to achieve by means of 'small talk', consequently, led a life on the afterburner of academic attention since. When it occurred it was often labelled as 'mundane' talk, that is: talk that demands not to be seen as full of substance and meaning, but can be analyzed merely as an instance of the universal formal mechanisms of human conversation (Briggs 1997 provides a powerful critique of this). Evidently, when the formal patterns of phatic communion are the sole locus of interest, not much is left to be said on the topic.

As mentioned, the perceived plenitude of phatic communion on the internet pushes us towards attention to such 'communication without content'. In what follows, we will engage with this topic and focus on a now-current internet phenomenon: memes. Memes will be introduced in the next section, and we shall focus on (a) the notion of 'viral spread' in relation to agentivity and consciousness, and (b) the ways in which we can see 'memes', along with perhaps many of the phenomena described by Miller, as forms of conviviality. In a concluding section, we will identify some important implications of this view.

\section{GOING VIRAL}

On January 21, 2012 Facebook CEO Mark Zuckerberg posted an update on his Facebook profile, introduced by 'Here's some interesting weekend reading' (figure 1). The message itself was 161 words long, and it led to a link to a 2000-word article. Within 55 seconds of being posted, the update got 932 'likes' and was 'shared' 30 times by other Facebook users. After two minutes, the update had accumulated 3,101 'likes' and 232 'shares'.

Given the structure and size of the text posted by Zuckerberg, it is quite implausible that within the first two minutes or so, more than 3,000 people had already read Zuckerberg's update and the article which it provides a link to, deliberated on its contents and judged it 'likeable'; and the same goes for the more than 200 times that the post had already been shared on other users' timelines. So what is happening here?

Some of the uptake can probably be explained with 'firsting', i.e. the preoccupation to be the first to comment on or 'like' an update on social mediamost clearly visible in the form of comments simply stating 'first!'. Another major explanation could be 'astroturfing': it is plausible that many of those who 'like' and 'share' Zuckerberg's update are in fact Facebook employees deliberately attempting to increase its visibility. We can guess, but we simply do not know. What we do know for sure, however, is that as a consequence of a first level of uptakepeople liking and sharing the post-there 


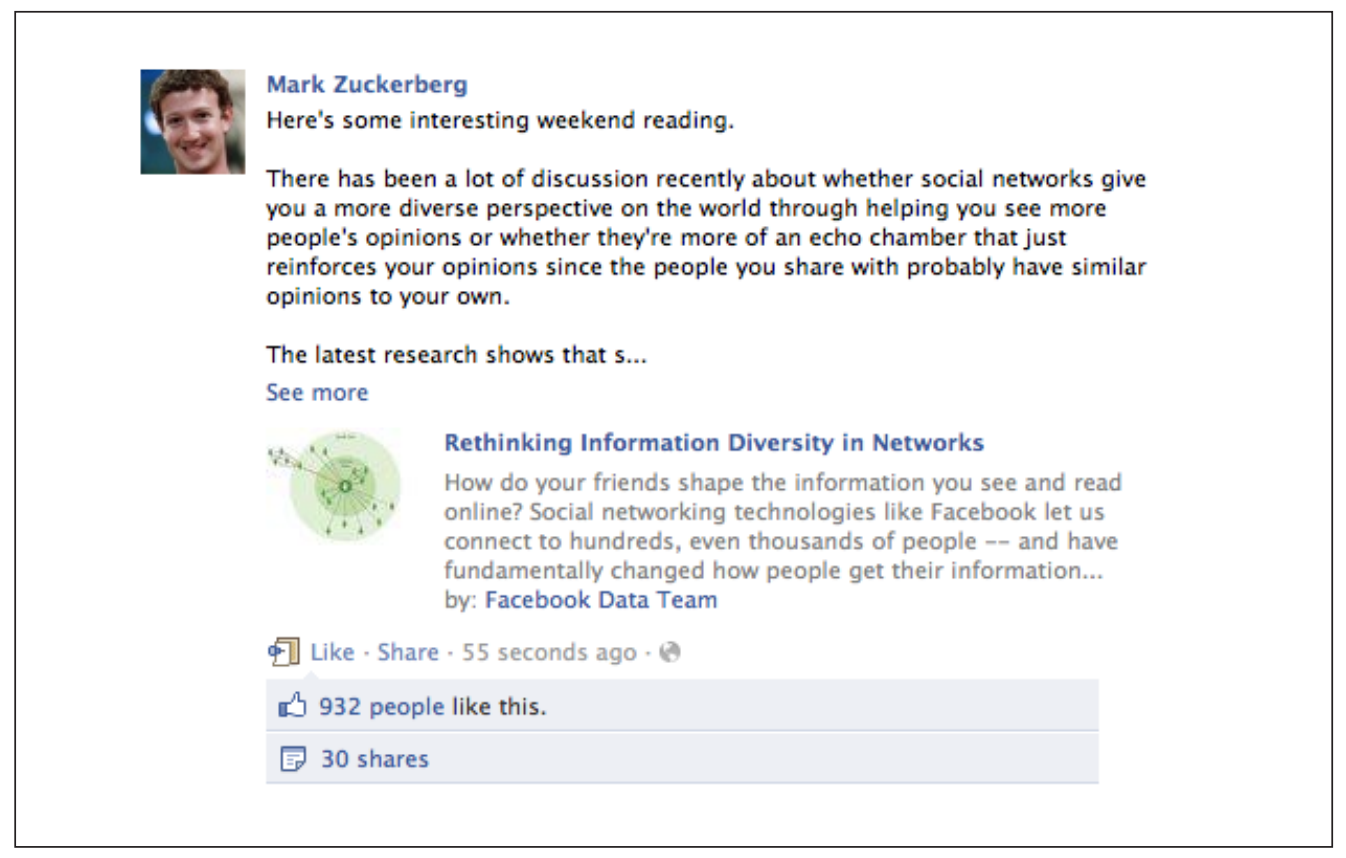

Figure 1: Screenshot of Zuckerberg's status update on Facebook, January 21, 2012

are further and further levels of uptake, as other users witness this liking and sharing activity (some of it may already be showing in the figures here), and consequently make inferences about the meaning of the post itself, but also about the person(s) in their network who reacted to it. Further layers of contextualisation are thus added to the original post, which may have an influence on the uptake by others.

Different social media platforms offer similar activity types: YouTube users can 'view' videos and 'like' or 'dislike' them, as well as adding 'comments' to them and adding videos to a profile list of preferences; Twitter users can create 'hashtags' and 'retweet' tweets from within their network; similar operations are possible on Instagram as well as on most local or regional social media platforms available throughout the world. Each time, we see that specific activities are made available for the rapid 'viral' spread of particular signs, while the actual content or formal properties of those signs do not seem to prevail as criteria for sharing, at least not when these properties are understood as denotational-semantic or aesthetic in the Kantian sense. We shall elaborate this below. The ace of virality after the first decade of the $21^{\text {st }}$ century is undoubtedly the South-Korean music video called Gangnam Style, performed by an artist called Psy: Gangnam Style was posted on YouTube on 15 July, 2012, and had been viewed 2,345475395 times on 30 May, 2015. Professional as well as lay observers appear to agree that the phenomenal virality of Gangnam Style was not due to the intrinsic qualities, musical, choreographic or otherwise, of the video. The hype was driven by entirely different forces.

The point to all of this, however, is that we see a communicative phenomenon of 
astonishing speed and scope: large numbers of people react on a message by expressing their 'liking' and by judging it relevant enough to share it with their 'friends' within their social media community. At the same time, in spite of Zuckerberg's message being textual, it was not read in the common sense understanding of this term. The 'like' and 'share' reactions, consequently, refer to another kind of decoding and understanding than the ones we conventionally use in text and discourse analysis-'meaning' as an outcome of denotational-textual decoding is not at stake here, and so the 'liking' and 'sharing' is best seen as 'phatic' in the sense of the terms discussed above. Yet, these phatic activities appear to have extraordinary importance for those who perform them, as 'firsting' and 'astroturfing' practices illustrate: people on social media find it very important to be involved in 'virality'. People find it important to be part of a group that 'likes' and 'shares' items posted by others. It is impossible to know-certainly in the case of Zuckerberg-who the members of this group effectively are (this is the problem of scope, and we shall return to it), but this ignorance of identities of group members does seem to matter less than the expression of membership by means of phatic 'likes' and 'shares'. What happens here is 'communion' in the sense of Malinowski: identity statements expressing, pragmatically and metapragmatically, membership of some group. Such groups are not held together by high levels of awareness and knowledge of deeply shared values and functions-the classical community of Parsonian sociology-but by loose bonds of shared, even if superficial interest or 'ambient affiliation' in Zappavigna's terms (2011: 801), enabled by technological features of social media affording forms of searchability and findability of 'like'minded people.

We need to be more specific though, and return to our Facebook example. 'Liking' is an identity statement directly oriented towards the author of the update-Zuckerberg-and indirectly inscribing oneself into the community of those who 'like' Zuckerberg, as well as indirectly flagging something to one's own community of Facebook 'friends' (who can monitor activities performed within the community). Patricia Lange (2009: 71), thus, qualifies such responsive uptake activities ('viewing' YouTube videos in her case) as forms of 'self-interpellation': people express a judgment that they themselves belong to the intended audiences of a message or sign. 'Sharing', by contrast, recontextualizes and directly reorients this statement towards one's own community, triggering another phase in a process of viral circulation, part of which can-but must not-involve real 'reading' of the text. Also, 'liking' is a responsive uptake to someone else's activity while 'sharing' is the initiation of another activity directed at another (segment of a) community. So, while both activities share important dimensions of phaticity with each other, important differences also occur. These distinctions, as noted, do not affect the fundamental nature of the interaction between actors and signs-'sharing', as we have seen, does not presuppose careful reading of the text-but there are differences in agency and activity type.

This is important to note, because existing definitions of virality would emphasize the absence of significant change in the circulation of the sign. Limor Shifman (2011: 190), for instance, emphasizes the absence of significant change to the sign itself to distinguish virality from 'memicity': memes, as opposed to viral signs, would involve 
changes to the sign itself. We shall see in a moment that this distinction is only valid when one focuses on a superficial inspection of the formal properties of signs. When one takes social semiotic activities as one's benchmark, however, things become more complicated and more intriguing. We have seen that significant distinctions apply to 'liking' and 'sharing'. In fact, we can see both as different genres on a gradient from phatic communion to phatic communication: there are differences in agency, in the addressees and communities targeted by both activities and in the fundamental pragmatic and metapragmatic features of both activities.

To clarify the latter: 'sharing' an update on Facebook is a classic case of 're-entextualization' (Bauman and Briggs 1990; Silverstein and Urban 1996) or 're-semiotization' (Scollon and Scollon 2004). Re-entextualization refers to the process by means of which a piece of 'text' (a broadly defined semiotic object here) is extracted from its original context-of-use and re-inserted into an entirely different one, involving different participation frameworks, a different kind of textuality-an entire text can be condensed into a quote, for instance-and ultimately also very different meaning outcomes. What is marginal in the source text can become important in the re-entextualized version, for instance. Re-semiotization, in line with the foregoing, refers to the process by means of which every 'repetition' of a sign involves an entirely new set of contextualization conditions and thus results in an entirely 'new' semiotic process, allowing new semiotic modes and resources to be involved in the repetition process (Leppänen et al. 2014). The specific affordances for responsive and sharing activities offered by social media platforms are thus not unified or homogeneous: we can distinguish a gradient from purely responsive uptake to active and redirected re-entextualization and resemiotization, blurring the distinction made by Shifman between virality and memicity.

Let us have a closer look at memes now, and focus again on the different genres of memic activity we can discern.

\section{THE WEIRD WORLD OF MEMES}

As we have seen, Shifman locates the difference between virality and memicity in the degree to which the sign itself is changed in the process of transmission and circulation. Memes are signs the formal features of which have been changed by users. For her definition, Shifman draws on Richard Dawkins, author of The Selfish Gene (1976), who coined 'meme' by analogy with 'gene' as 'small cultural units of transmission (...) which are spread by copying or imitation' (Shifman 2011: 188). We have already seen, however, that even simple 'copying' or 'imitation' activities such as Facebook 'sharing' involve a major shift in activity type called re-entextualization. Memes, often multimodal signs in which images and texts are combined, would typically enable intense resemiotization as well, in that original signs are altered in various ways, generically germane-a kind of 'substrate' recognizability would be maintained-but situationally adjusted and altered so as to produce very different communicative effects. Memes tend to have an extraordinary level of semiotic productivity which involves very different kinds of semiotic activitygenres, in other words.

Let us consider figures 2-4, and 5-7. In figure 2 we see the origin of a 
successful meme, a British World War II propaganda poster.

A virtually endless range of resemiotized versions of this poster have gone viral since the year 2000. They can be identified as intertextually related by the speech act structure of the message (an adhortative 'keep calm' or similar statements, followed by a subordinate adhortative) and the graphic features of lettering and layout (larger fonts for the adhortatives, the use of a coat of arms-like image). Variations on the memic theme range from minimal to maximal, but the generic template is constant. Figure 3 shows a minimally resemiotized variant in which lettering and coat of arms (the royal crown) are kept, while in figure 4 ,

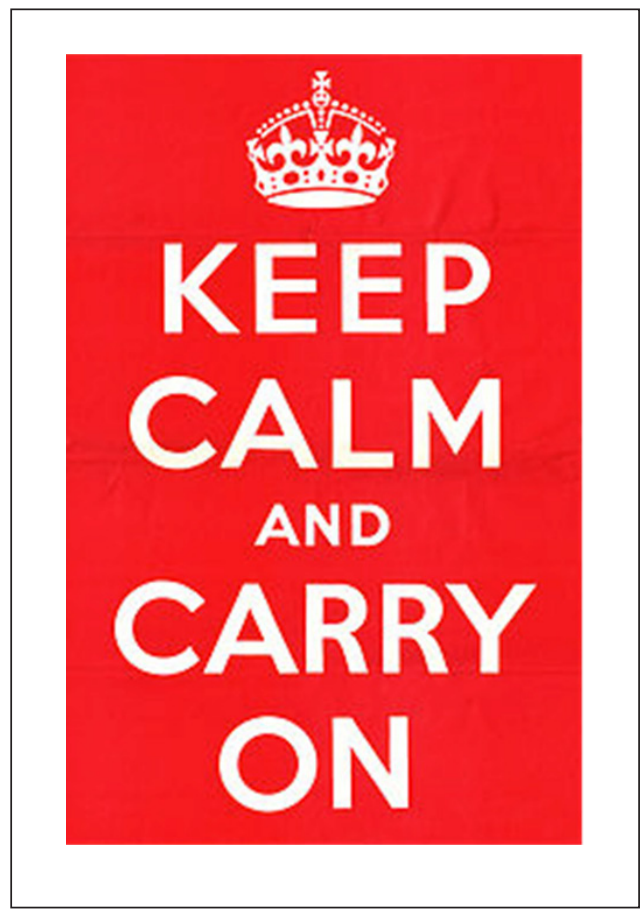

Figure 2: British wartime propaganda poster the royal crown has been replaced by a beer mug.

In figures 2, 3, and 4 we see how one set of affordances- the visual architecture of the sign and its speech act formatbecomes the intertextual link enabling the infinite resemiotizations while retaining the original semiotic pointer: most users of variants of the meme would know that the variants derive from the same 'original' meme. The visual architecture and speech act format of the 'original', thus, are the 'mobile' elements in memicity here: they provide memicintertextual recognisability, while the textual adjustments redirect the meme towards more specific audiences and reset it in different frames of meaning and use.

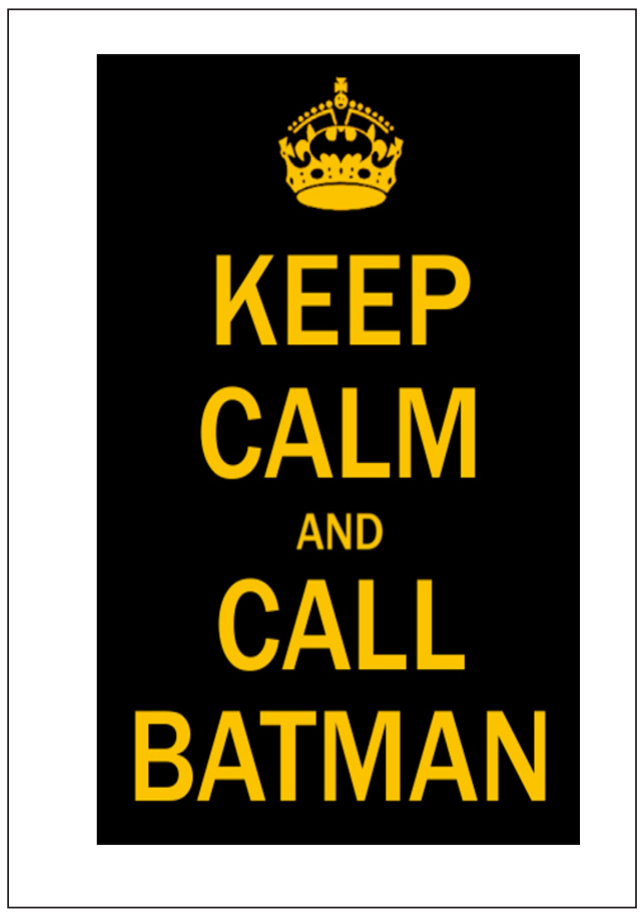

Figure 3: Keep calm and call Batman

See http://knowyourmeme.com/memes/keep-calm-and-carry-on for figures 2-4 


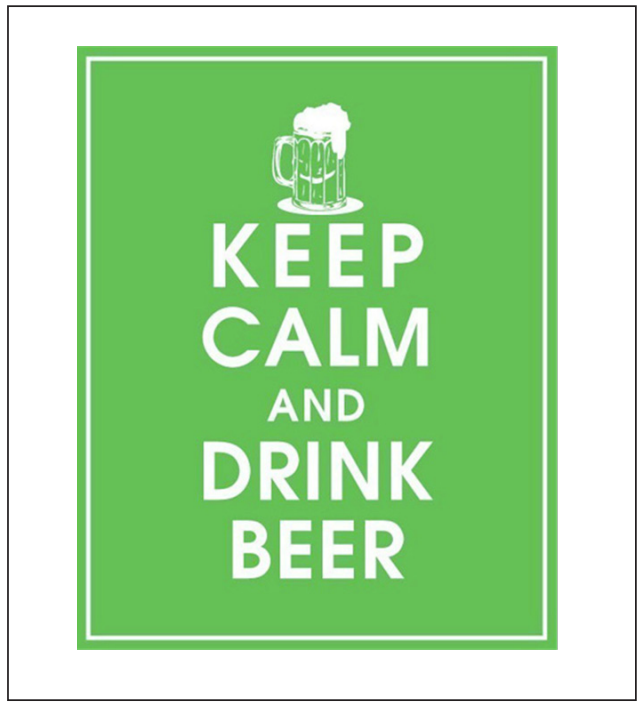

Figure 4: Keep calm and drink beer

The opposite can also apply, certainly when memes are widely known because of textual-stylistic features: the actual ways in which 'languaging' is performed through fixed expressions and speech characteristics. A particularly successful example of such textualstylistic memicity is so-called 'lolspeak', the particular pidginized English originally associated with funny images of cats ('lolcats'), but extremely mobile as a memic resource in its own right. Consider figures 5, 6, and 7. Figure 5 documents the origin of this spectacularly successful meme: a picture of a cat, to which the caption 'I can has cheezburger?' was added, went viral in 2007 via a website 'I can has cheezburger?'. The particular caption phrase went viral as well and became tagged to a wide variety of other images - see figure 6. The caption, then, quickly became the basis for a particular pidginized variety of written English, which could in turn be deployed in a

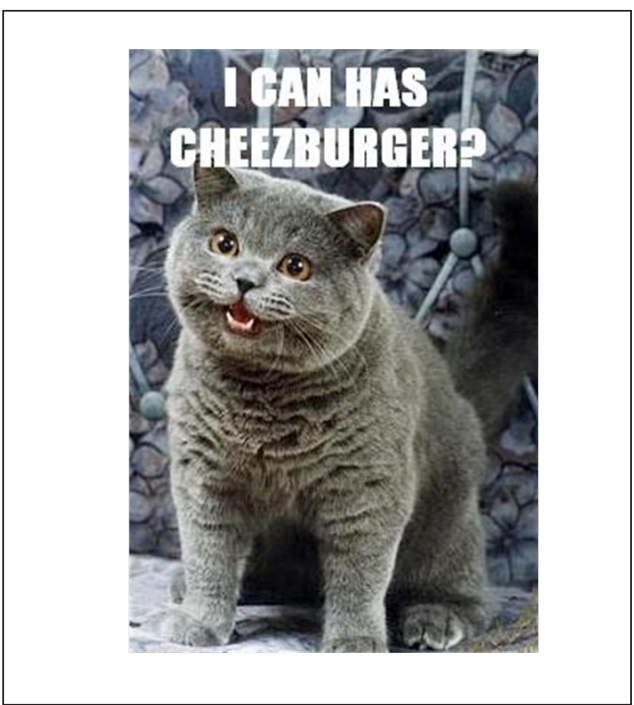

Figure 5: I can has cheezburger?

See http://knowyourmeme.com/memes/ sites/cheezburger

broad range of contexts (see figure 7). The extraordinary productivity of this meme-turned-language-variety was demonstrated in 2010, when a team of 'lolspeak' authors completed an online translation of the entire Bible in their self-constructed language variety. The Lolcat Bible can now also be purchased as a book.

The different resources that enter into the production of such memes can also turn out to be memic in themselves. People, as we said, are extraordinarily creative in reorganizing, redirecting, and applying memic resources over a vast range of thematic domains, addressing a vast range of audiences while all the same retaining clear and recognizable intertextual links to the original memic sources. This fundamental intertextuality allows for combined memes, in which features of different established memes are blended in a 'mashup' meme. Figure 8 shows such a mashup meme. 


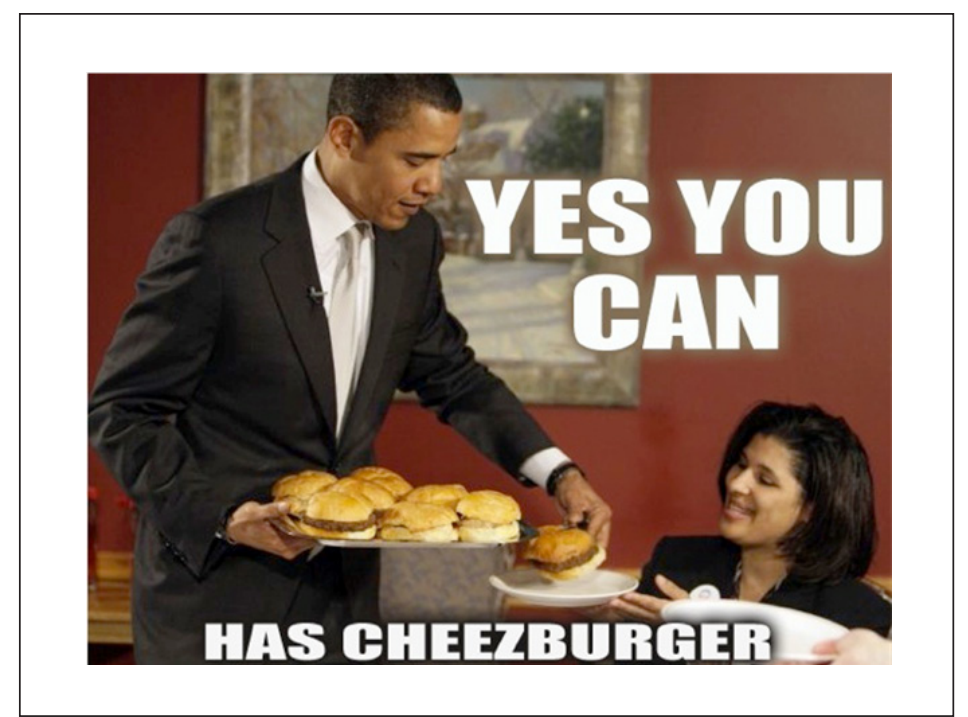

Figure 6: President and a possible voter having cheezburger.

See http://www.myconfinedspace.com/2008/04/18/barack-obama-yes-you-can/.

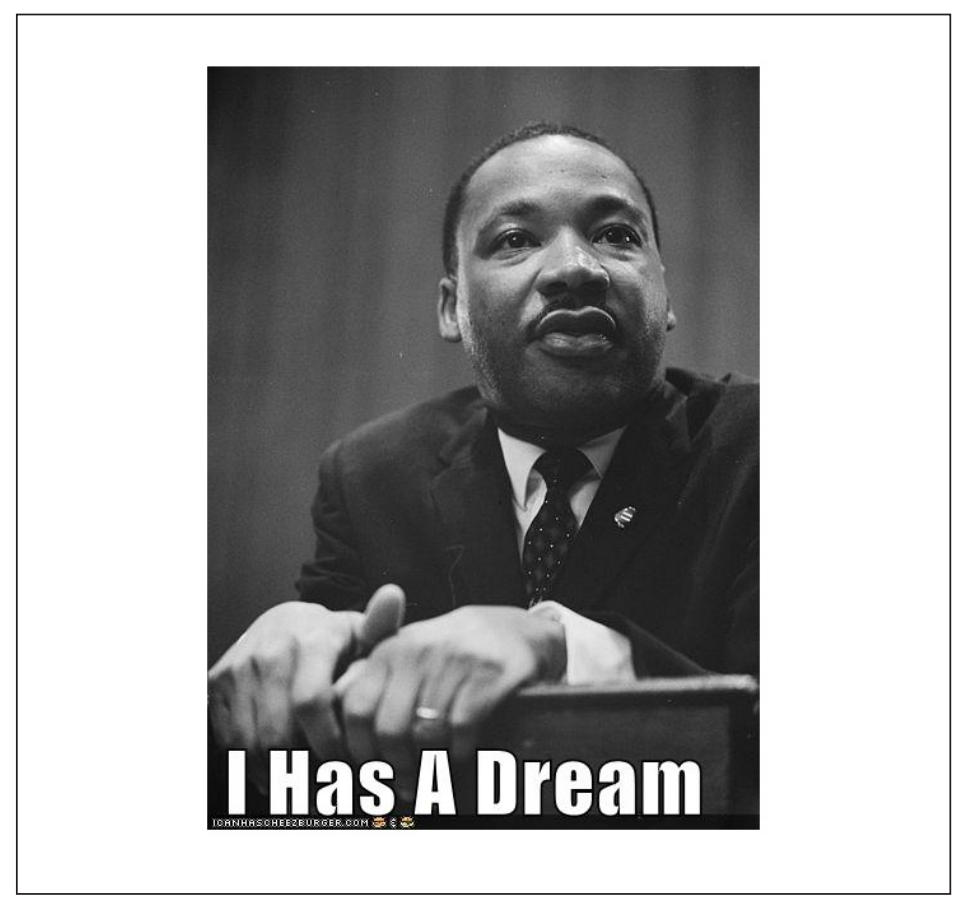

Figure 7: I has a dream.

See http://memebase.cheezburger.com/puns/tag/martin-luther-king-jr.

(C) Varis, Blommaert and CMDR. 2015 


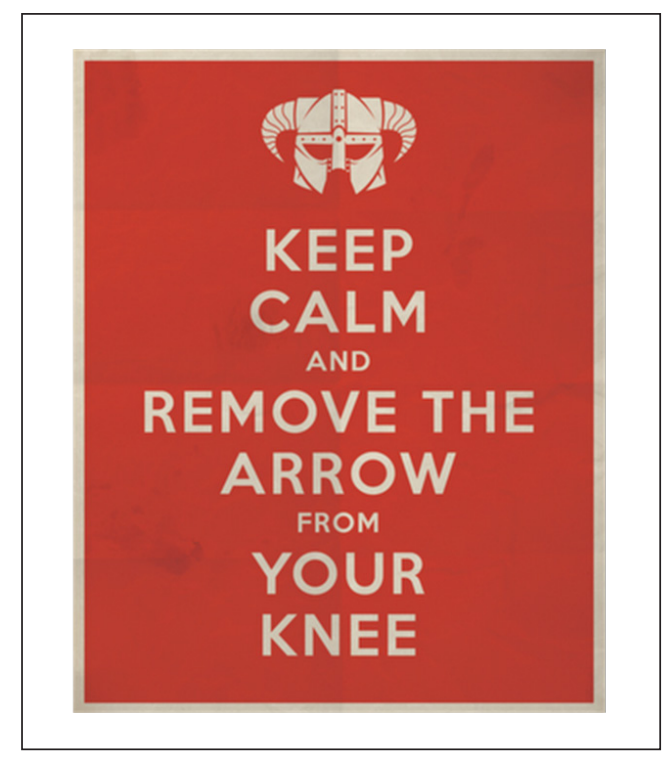

Figure 8: Keep calm and remove the arrow from your knee

See https://www.facebook.com/pages/Keep-Calm-and-remove-the-arrow-from-yourknee/254461191300457.

We see the familiar template of the 'Keep calm' meme, to which a recognizable reference to another meme is added. The origin of this other meme, 'then I took an arrow in the knee', is in itself worthy of reflection, for it shows the essentially arbitrary nature of memic success. The phrase was originally uttered by characters in the video game 'Skyrim' (figure 9). The phrase is quite often repeated throughout the game, but this does not in itself offer an explanation for the viral spread of the expression way beyond the community of Skyrim gamers.

The phrase became wildly productive and can now be tagged to an almost infinite range of different expressions, each time retaining a tinge of its original apologetic character, and appearing in mashups, as we saw in figure 8 .

What we see in each of these examples is how memes operate via a combination of intertextual recognizability and individual creativity-individual users adding an 'accent' to existing viral memes, in attempts to go viral with their own adapted version. Thework of resemiotization involved in such processes can be complex and demanding. Mashup memes, for instance, involves elaborate knowledge of existing memes, an understanding of the affordances and limitations for altering the memes, and graphic, semiotic, and technological skills to post them online. The different forms of resemiotization represent different genres of communicative action, ranging from maximally transparent refocusing of existing memes to the creation of very different and new memes, less densely connected to existing ones.

Two points need to be made now. First, we do not see such resemiotizations, even drastic and radical ones, as being fundamentally different from the 'likes' and 'shares' we discussed in the previous section. We have seen that 'likes' and 'shares' are already different genres characterized by very different activity patterns, orientations 


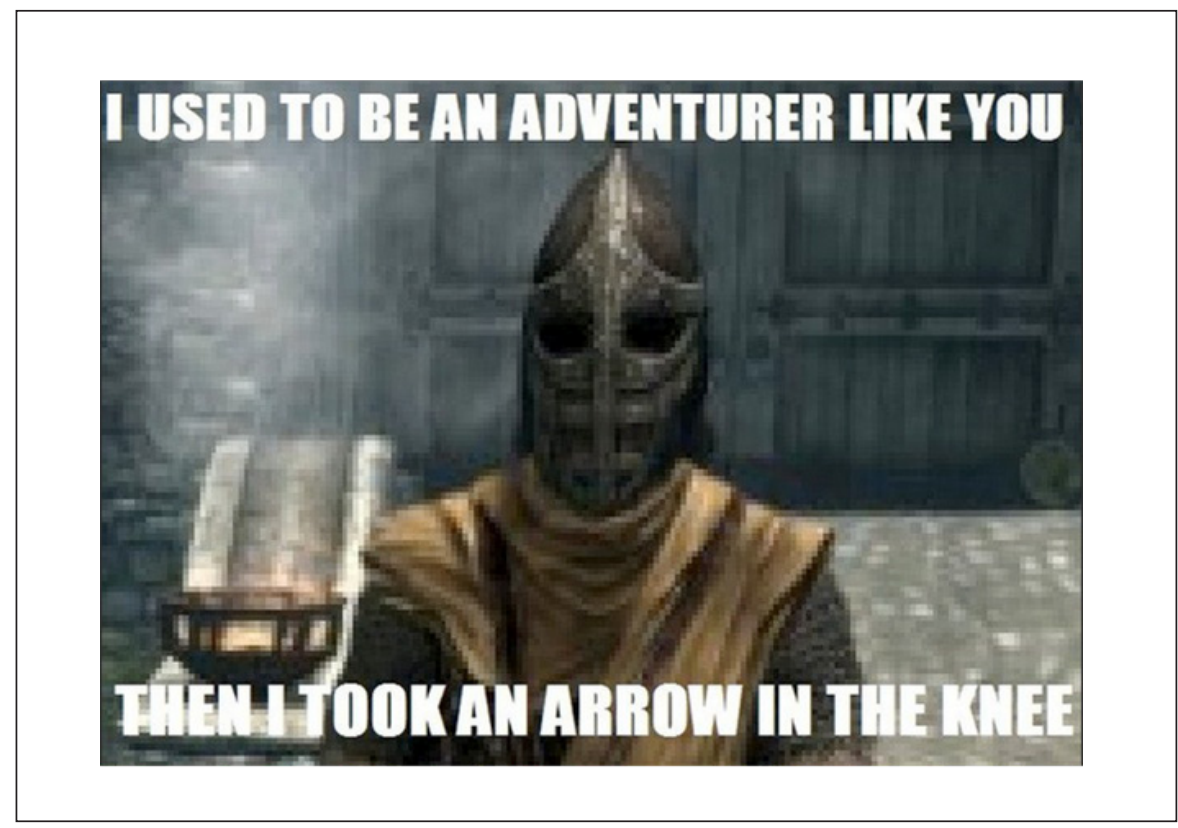

Figure 9: Skyrim scene 'Then I took an arrow in the knee'. See http://knowyourmeme. com/memes/i-took-an-arrow-in-the-knee.

to addressees and audiences, and degrees of intervention in the original signs. The procedures we have reviewed here differ in degree but not in substance: they are, like 'retweets', 'likes' and 'shares', re-entextualizations of existing signs, i.e. meaningful communicative operations that demand different levels of agency and creativity of the user. Second, and related to this, the nature of the original sign itself-its conventionally understood 'meaning'-appears to be less relevant than the capacity to deploy it in largely phatic, relational forms of interaction. This again, ranges from what Malinowski described as 'communion'-ritually expressing membership of a particular communityto 'communication' within the communities we described as held together by 'ambient affiliation'. 'Meaning' in its traditional sense needs to give way here to a more general notion of 'function'. Memes, just like Mark Zuckerberg's status updates, do not need to be read in order to be seen and understood as denotationally and informationally meaningful; their use and re-use appear to be governed by the 'phatic' and 'emblematic' functions often seen as of secondary nature in discourse-analytic literature.

\section{Conviviality on demand}

But what explains the immense density of such phatic forms of practice on social media? How do we make sense of the astonishing speed and scope with which such phatic forms of communion and communication circulate, creatinglike in the case of Gangnam Styleperhaps the largest-scale collective communicative phenomena in human history? The explanations, we hope to have shown, do not necessarily have to be located in the features of the signs themselves, nor in the specific practices they prompt—both are unspectacular. So 
perhaps the explanations must be sought in the social world in which these phatic practices make sense.

In a seminal paper, Alice Marwick and danah boyd (2010: 120) distinguish between email and Twitter. They have this to say on the topic:

(...) the difference between Twitter and email is that the latter is primarily a directed technology with people pushing content to persons listed in the 'To:' field, while tweets are made available for interested individuals to pull on demand. The typical email has an articulated audience, while the typical tweet does not.

The statement demands nuancing, for we have seen that even minimal forms of activity such as 'sharing' involve degrees of audience design-the seemingly vacuous identity statements we described above, lodged in social media practices, are always directed at some audience, of which users have some idea, right or wrong (cf. Androutsopoulos 2013). Imaginary audiences are powerful actors affecting discursive behaviour, as Goffman and others have shown so often (e.g. Goffman 1963), and Marwick and boyd's early statement that 'Twitter flattens multiple audiences into one'-a phenomenon they qualify as 'context collapse'-is surely in need of qualification (Marwick and boyd 2010: 122). The intricate socialsemiotic work we have described here certainly indicates users having diverse understandings of audiences on social media. Different social media platforms offer opportunities for different types of semiotic and identity work and users often hold very precise and detailed views of what specific platforms offer them in the way of audience access, identity and communication opportunities, and effects (cf. Gershon 2010).
At the same time, Marwick and boyd are correct in directing our attention towards the kinds of communities in which people move on social media. In spite of precise ideas of specific target audiences and addressees, it is certainly true that there is no way in which absolute certainty about the identities (and numbers) of addressees can be ascertained on most social media platforms-something which Edward Snowden also made painfully clear. In addition, it is true that lump categories such as Facebook 'friends' gather a range of-usually never explicitly definedsubcategories ranging from 'offline friends' and close relatives to what we may best call, following Goffman again, 'acquaintances'. Goffman (1963), as we know, described acquaintances as that broad category of people within the network of US middle class citizens with whom relations of sociality and civility need to be maintained. Avoidance of overt neglect and rejection are narrowly connected to avoidance of intimacy and 'transgressive' personal interaction: what needs to be maintained with such people is a relationship of conviviality - a level of social intercourse characterized by largely 'phatic' and 'polite' engagement in interaction. Acquaintances are not there to be 'loved', they are there to be 'liked'. Facebook is made exactly for these kinds of social relationships (van Dijck 2013), which is perhaps also why a discourse analysis of Facebook interaction reveals the overwhelming dominance of the Gricean Maxims, that old ethnotheory of 'polite' US bourgeois interaction (Varis forthcoming).

But let us delve slightly deeper into this. The communities present as audiences on social media may be at once over-imagined and under-determined: while users can have relatively precise ideas of who it is they are addressing, a level of indeterminacy is inevitable in 
reality. This means, in analysis, that we cannot treat such communities in the traditional sense of 'speech community' as a group of people tied together by clear and generally shareable rules of the indexical value and function of signs (Agha 2007). Indexical orders need to be built, as a consequence, since they cannot readily be presupposed. Virality, as a sociolinguistic phenomenon, might be seen as moments at which such indexical orders-perceived shareability of meaningful signs-are taking shape. The two billion views of Gangnam Style suggest that large numbers of people in various places on earth recognized something in the video; what it is exactly they experienced as recognizable is hard to determine and research on this topic-how virality might inform us on emergent forms of social and cultural normativity in new and unclear large globalized human collectives-is long overdue.

Some suggestionsin this direction can be offered, though. In earlier work, we tried to describe ephemeral forms of community formation in the onlineoffline contemporary world as 'focused but diverse' (Blommaert and Varis 2013). Brief moments of focusing on perceived recognizable and shareable features of social activity generate temporary groups-think of the thousands who 'liked' Zuckerberg's status update-while such groups do not require the kinds of strong and lasting bonds grounded in shared bodies of knowledge we associate with more traditionally conceived 'communities' or 'societies'. In fact, they are groups selected on demand, so to speak, by individual users in the ways we discussed earlier. People can focus and re-focus perpetually, and do so (which explains the speed of virality) without being tied into a community of fixed circumscription, given the absence of the deep and strong bonds that tie them together, and the absence of temporal and spatial co-presence that characterizes online groups (cf. Maly and Varis forthcoming on 'micro-populations').

A joint 'phatic' focus on recognizable form or shape offers possibilities for such processes of groupness, while the actual functional appropriation and deployment of signs-what they actually mean for actual users-is hugely diverse; the infinite productivity of memesthe perpetual construction of memic 'accents'-illustrates this. Here we begin to see something fundamental about communities in an online age-the joint focusing, even if 'phatic', is in itself not trivial: it creates a structural level of conviviality, i.e. a sharing at one level of meaningful interaction by means of a joint feature, which in superficial but real ways translates a number of individuals into a focused collective. Note, and we repeat, that what this collective shares is the sheer act of phatic communion (the 'sharing' itself, so to speak), while the precise meaning of this practice for each individual member of the collective is impossible to determine. But since Malinowski and Goffman, we have learned not to underestimate the importance of (seemingly) unimportant social activities. Memes force us to think about levels of social structuring that we very often overlook because we consider them meaningless.

This neglect of conviviality has effects. In the superdiversity that characterizes online-offline social worlds, we easily tend to focus on differences and downplay the level of social structuring that actually prevents these differences from turning into conflicts. Recognizing such hitherto neglected levels of social structuring might also serve as a corrective to rapid qualifications of the present era as being 'postsocial'-a point on which we disagree with Vincent Miller. 
There is a great deal of sociality taking place on social media, but this sociality might require a new kind of sociological imagination. We will look in vain for communities and societies that resemble the ones proposed by Durkheim and Parsons. But that does not mean that such units are not present, and even less that they are not in need of description.

\section{REFERENGES}

Agha, Asif. 2007. Language and Social Relations. Cambridge: Cambridge University Press.

Androutsopoulos, Jannis. 2013. Networked multilingualism: Some language practices on Facebook and their implications. International Journal of Bilingualism 0 (0): 1-21.

Bauman, Richard and Charles Briggs. 1990. Poetics and performance as critical perspectives on language and social life. Annual Review of Anthropology 19: 59-88.

Blommaert, Jan and Piia Varis. 2013. Life projects. Tilburg Papers in Culture Studies, Paper 58. < https:// www.tilburguniversity.edu/ upload/c37dcccf-242d-4fcab79f-d3d366b0a505_TPCS_58_

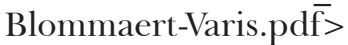

Briggs, Charles. 1997. Introduction: From the ideal, the ordinary, and the orderly to conflict and violence in pragmatic research. Pragmatics 7 (4) (special issue on Conflict and Violence in Pragmatic Research, ed. Charles Briggs): 451-459.

Dawkins, Richard. 1976. The Selfish Gene. Oxford: Oxford University Press.

Van Dijck, José. 2013. The Culture of Connectivity. A Critical History of Social Media. Oxford: Oxford University Press.

Gershon, Ilana. 2010. Breakup 2.0. Disconnecting over New Media. Ithaca: Cornell University Press.

Goffman, Erving. 1963. Behavior in Public Places. New York: The Free Press.

Goffman, Erving. 1967. Interaction Ritual: Essays on Face-to-face Behavior. New York: Doubleday Anchor.
Hymes, Dell. 1972/1986. Models of the interaction of language and social life. In John Gumperz and Dell Hymes (eds). Directions in Sociolinguistics: The Ethnography of Communication. London: Blackwell. 35-71.

Jakobson, Roman. 1960. Linguistics and poetics. In Thomas Sebeok (ed). Style in Language. Cambridge: MIT Press. 350-377.

Lange, Patricia G. 2009. Videos of affinity on YouTube. In Pelle Snickars and Patrick Vonderau (eds). The YouTube Reader. Stockholm: National Library of Sweden. 70-88.

Leppänen, Sirpa, Samu Kytölä, Henna Jousmäki, Saija Peuronen and Elina Westinen. 2014. Entextualization and resemiotization as resources for identification in social media. In Philip Seargeant and Caroline Tagg (eds). The Language of Social Media: Identity and Community on the Internet. Houndmills: Palgrave Macmillan. 112-136.

Malinowski, Bronislaw. 1923/1936. The problem of meaning in primitive languages. In C.K. Ogden and I.A. Richards (eds). The Meaning of Meaning. London: Kegan Paul. 296-336.

Maly, Ico and Piia Varis. Forthcoming. The $21^{\text {st }}$-century hipster: On micropopulations in times of superdiversity. European Journal of Cultural Studies.

Marwick, Alice E. and danah boyd. 2010. I tweet honestly, I tweet passionately: Twitter users, context collapse, and the imagined audience. New Media E Society 13 (1): 114-133.

Miller, Vincent. 2008. New media, networking and phatic culture. Convergence 14: 387-400.

Schegloff, Emanuel. 1972/1986. Sequencing in conversational openings. In John Gumperz and Dell Hymes (eds). Directions in Sociolinguistics: The Ethnography of Communication. London: Blackwell. 346-380.

Schegloff, Emanuel. 1988. Goffman and the analysis of conversation. In Paul Drew and Anthony Wootton (eds). Erving 
Goffman: Exploring the Interaction Order. Oxford: Polity Press. 89-135.

Schegloff, Emanuel and Harvey Sacks.

1973. Opening up closings. Semiotica 8: 289-327.

Scollon, Ron and Suzie Wong Scollon. 2004. Nexus Analysis: Discourse and the Emerging Internet. London: Routledge.

Senft, Gunter. 1995. Phatic communion. In Jef Verschueren, Jan-Ola Östman and Jan Blommaert (eds). Handbook of Pragmatics 1995. Amsterdam: John Benjamins. 1-10.
Shifman, Limor. 2011. An anatomy of a YouTube meme. New Media E Society 14 (2): 187-203.

Silverstein, Michael and Greg Urban. 1996. Natural Histories of Discourse. Chicago: University of Chicago Press.

Varis, Piia. forthcoming. Facebook and the Gricean maxims.

Zappavigna, Michele. 2011. Ambient affiliation: A linguistic perspective on Twitter. New Media E Society 13 (5): 788-806. 